\title{
Spatial variability of mixing in the Southern Ocean
}

\author{
B. M. Sloyan ${ }^{1}$ \\ Department of Physical Oceanography, Woods Hole Oceanographic Institution, Woods Hole, Massachusetts, USA \\ Received 24 May 2005; revised 7 August 2005; accepted 10 August 2005; published 16 September 2005.
}

[1] Strain variance from standard hydrographic profiles in the southern hemisphere oceans shows that turbulent mixing is vertically and spatially non-uniform. In the South Atlantic, Indian and South Pacific Oceans, enhanced diffusivities are found over rough topography. Consistent with internal tide generated mixing, the water column diffusivity returns to background levels $500 \mathrm{~m}$ to $1000 \mathrm{~m}$ off the sea floor. In the Southern Ocean, enhanced diffusivities throughout the entire water column below $1500 \mathrm{~m}$ are found in the Antarctic Circumpolar Current over complex topography. Differences in the vertical extent of enhanced diffusivity profiles in the Antarctic Circumpolar Current between the parameterizations based on tidal models and topography and of the present estimate of strain variance imply that elevated vertical diffusivity profiles in the Southern Ocean are due to the interaction between the mean geostrophic current and bottom topography. Citation: Sloyan, B. M. (2005), Spatial variability of mixing in the Southern Ocean, Geophys. Res. Lett., 32, L18603, doi:10.1029/2005GL023568.

\section{Introduction}

[2] The meridional overturning circulation refers to the flow of bottom and deep waters away from their high latitude sources and the compensating return flow of less dense water. The sources of deep and bottom water are limited to a few high latitude sites in the present-day ocean - namely the North Atlantic and a few sites near the Antarctic continental margin. High salinity North Atlantic Deep Water (NADW) flows southward into the Southern Ocean. In the Southern Ocean, NADW overlies Lower Circumpolar Deep Water (LCDW) and Antarctic Bottom Water (AABW), both of southern ocean origin. Diapycnal fluxes of mass, heat, salt and other properties, by upwelling across isopycnals somewhere in the world's oceans, are one component in the closure of the NADW, LCDW and AABW circulation. The diapycnal fluxes in the southern hemisphere oceans (Southern Ocean and subtropical South Atlantic, South Pacific and Indian Oceans) are therefore a key element of the global meridional overturning circulation.

[3] For dynamical clarity, and lacking observational evidence of where the required upwelling occurred, Stommel and Arons [1960] developed a theory of the deep ocean circulation based on the assumption of uniform upwelling throughout the world's oceans. Recently, observational estimates of mixing have questioned the validity of uniform

${ }^{1}$ CSIRO Marine and Atmospheric Research, Hobart, Tasmania, Australia. upwelling. Limited direct observations of turbulent mixing in the ocean interior suggest that diapycnal mixing, and hence upwelling, is spatially nonuniform [Toole et al., 1994; Polzin et al., 1997]. Microstructure observations have found weak mixing ( $\kappa \leq 10^{-5} \mathrm{~m}^{2} \mathrm{~s}^{-1}$ ) over abyssal plains and smooth topography, while enhanced mixing was found over rough mid-ocean ridges and isolated topography [Polzin et al., 1996; Toole et al., 1997; St. Laurent et al., 2001]. Extending the microstructure observations of enhanced mixing to the basin domain in which they were taken indicates that deep mixing plays an important role in the abyssal circulation [Toole et al., 1997; St. Laurent et al., 2001; Morris et al., 2001]. These observations have renewed interest in the possibility that intense mixing at specific ocean sites dominates the net diapycnal mixing required to maintain the abyssal stratification and close the meridional overturning circulation.

[4] In this paper I estimate vertical mixing for the Southern Ocean and adjacent subtropical Oceans from the World Ocean Circulation Experiment (WOCE) Conductivity-Temperature-Depth (CTD) sections. The results show that mixing in these regions is spatially non-uniform and dominated by numerous mixing "hotspots" over complex topographic features.

\section{Method}

[5] To estimate diffusivity from the CTD profile data I apply the scaling formula for estimating the dissipation of turbulent kinetic energy $(\epsilon)$ based on finescale strain $(\xi)$ [Wijesekera et al., 1993]

$$
\epsilon_{\xi}=7 \times 10^{-10} \frac{\left\langle N^{2}\right\rangle}{N_{o}^{2}} \frac{\left\langle\xi_{z}^{2}\right\rangle^{2}}{\left[\xi_{G M}^{2}\right]^{2}} \mathrm{Wkg}^{-1}
$$

where $N_{o}$ (buoyancy frequency) is the reference $\mathrm{N}$ used by Garrett and Munk [1975] (hereinafter referred to as GM); $7 \times 10^{-10} \mathrm{~W} \mathrm{~kg}^{-1}$ is the dissipation in the background GM wave field at $N=N_{o}\left(=5.2 \times 10^{-3} \mathrm{rad} \mathrm{s}^{-1}\right)$ and $30^{\circ}$ of latitude; $\xi_{G M}^{2}$ is the strain variance of the modified GM wave field [Cairns and Williams, 1976]; and $\xi_{z}^{2}$ is the strain variance of the internal wave field. Angle brackets denote an averaging process.

[6] The relationship between the dissipation rate of turbulent kinetic energy $(\epsilon)$ and buoyancy flux is [Osborn, 1980]:

$$
\epsilon=\Gamma^{-1} \kappa_{z} N^{2}
$$

where the diffusivity is

$$
\kappa_{z}=\Gamma \frac{\epsilon}{N^{2}}
$$




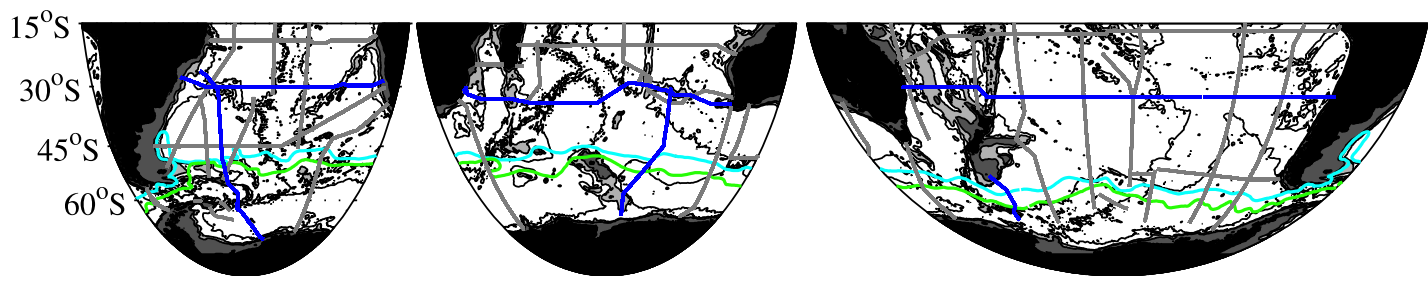

Figure 1. WOCE sections used to calculate order of magnitude estimates of mixing (solid grey and blue lines). The sections used in the vertical distribution of mixing at $30^{\circ} S$ (Figure 2) and across the Antarctic Circumpolar Current (Figure 3) are shown in blue. The position of the Subantarctic (light blue solid line) and Antarctic Polar (green solid line) Fronts are also shown [Orsi et al. 1995].

The mixing efficiency, by physical arguments is $\Gamma \leq 0.2$. Substitution of $\epsilon_{\xi}$ into (3) gives an expression for $\kappa$ from strain variance:

$$
\kappa_{z}=7 \times 10^{-10} \Gamma \frac{1}{N_{o}^{2}} \frac{\left\langle\xi_{z}^{2}\right\rangle^{2}}{\left[\xi_{G M}^{2}\right]^{2}} \mathrm{~m}^{2} \mathrm{~s}^{-1}
$$

where $\xi_{z}$ is defined as $\xi_{z}=\frac{\left(N^{2}-\overline{N^{2}}\right)}{\left(\overline{N^{2}}\right)}$ and strain variance of the GM wave field is given as $\xi_{G M}^{2}=\frac{7}{3}\left\{\left(\frac{\lambda_{z}}{2}\right)\right\}^{-1} \cdot \lambda_{z}$ is the minimum wavelength for which $\xi$ was calculated and was determined from the spectral analysis of the vertical density profiles. $\frac{\lambda_{z}}{2}$ plays the same role of accounting for unresolved variance as Gregg's [1989, equation (24)] shear formula. A similar approach to estimate $\kappa_{z}$ from strain variance has been used by Mauritzen et al. [2002] and Kunze [2003].

[7] As was done by Mauritzen et al. [2002], $\xi_{z}$ is calculated from CTD profiles where it is assumed that (1) large vertical length scales in the density profiles represent the time mean $\left(\overline{N^{2}}\right)$. (2) Small vertical length scales do not contain any time mean signal and represent the internal wave field $\left(N^{2}\right)$. CTD data above the permanent pycnocline and within $200 \mathrm{~m}$ of the bottom were removed from each profile. In this study $\overline{N^{2}}$ is calculated over $500 \mathrm{~m}$. The vertical length scale $\left(\Delta Z \stackrel{\simeq}{=} \frac{\lambda_{z}}{2}\right)$ for calculation of $N^{2}$ was determined by spectral analysis of the vertical density profiles of the Southern Ocean CTD data (Figure 1). In the subtropical and subpolar regions the power spectra were nearly flat for wavelengths longer than $\lambda_{z}=60-80 \mathrm{~m}$. A sharp change in slope of the power spectra was seen at smaller wavelengths due to the resolution of the data. Across all wavelengths the power spectra for stations adjacent to the Antarctic continent were dominated by noise. Therefore, these CTD profiles were excluded from this study because measurement noise in the CTD salinity sensor is thought to dominate the density variability in this weakly stratified environment. $N^{2}$ was calculated over $\Delta Z=$ $40 \mathrm{~m}$. Vertical profiles of $\overline{N^{2}}$ and $N^{2}$ over their respective vertical intervals are estimated as linear fits to the specific volume anomaly depth profiles using the adiabatic leveling method [Bray and Fofonoff, 1981].

[8] In the development of (1)-(4) a number of assumptions have been made that may not be entirely appropriate for the Southern Ocean or the oceanic internal wave field. In the Scotia Sea [Naveira Garabato et al., 2004] a shear-tostrain ratio of 8 to 12 is found, while the application of (1) assumes a ratio of 3. Gargett [1990] points out that correction for unresolved variance may bias estimates of $\epsilon$ in high amplitude wave states. The combined errors from these assumptions may lead to errors in $\kappa_{z}$ of a factor of 2 to 5. This study, considering the above errors and the use of CTD data, therefore, only provides order of magnitude estimates of mixing and compares the spatial pattern of mixing between sections to assess the likely variability of mixing in the ocean. The validity of the assumptions contained in (1)-(4) should be tested with fine and microstructure observations.

\section{Results}

[9] WOCE hydrographic stations were used to estimate vertical profiles of diffusivity in the subtropical South Atlantic, Indian and South Pacific Oceans, and the Southern Ocean (Figure 1). In all sections, increased diffusivities 1 to 2 orders of magnitude larger than background values are found 500 to $1000 \mathrm{~m}$ above rough topography [Jayne and St. Laurent, 2001; Jayne et al., 2004], including mid-ocean ridges and isolated topographic features (Figures 2 and 3 ).

[10] Enhanced diffusivities are also found in individual basins of the trans-ocean sections, notably the Cape Basin (Atlantic Ocean), Perth Basin (Indian Ocean) and Southwest Pacific Basin immediately east of the Kermadec Ridge (Pacific Ocean) (Figure 2). Enhanced abyssal diffusivity in the Perth Basin is consistently found in CTD profiles in this basin (B. M. Sloyan (2005), Antarctic Bottom and Lower Circumpolar Deep Water circulation in the eastern Indian Ocean, submitted to Journal of Geophysical Research, 2005, hereinafter referred to as Sloyan, submitted manuscript, 2005). Sloyan (submitted manuscript, 2005) show that high abyssal diffusivity in the Perth Basin are found at the basin boundaries and over topographic features in the interior of the Basin. The bottom topography of the Southwest Pacific Basin is not smooth (Figure 2c). As in the Perth Basin, the complex topography may result in the enhanced abyssal mixing in this Basin.

[11] In the Southern Ocean enhanced diffusivities are found over rough topography including mid-ocean ridges and isolated topographic features and in the ACC fronts Antarctic Polar Front (APF) and Subantarctic Front (SAF) - over complex topography along its circumpolar path (Figure 3). The meridional sections in the Atlantic and Indian sectors of the Southern Ocean show enhanced mixing over topography - Scotia Arc between $55^{\circ}$ and $60^{\circ} \mathrm{S}$ in the Atlantic sector and Southeast Indian Ridge between $44^{\circ}$ and $46^{\circ} \mathrm{S}$ in the Indian sector. Enhanced mixing over the Southeast Indian Ridge is confined to within approximately $1000 \mathrm{~m}$ above the bottom, although a narrow band of enhanced diffusivity throughout much of 

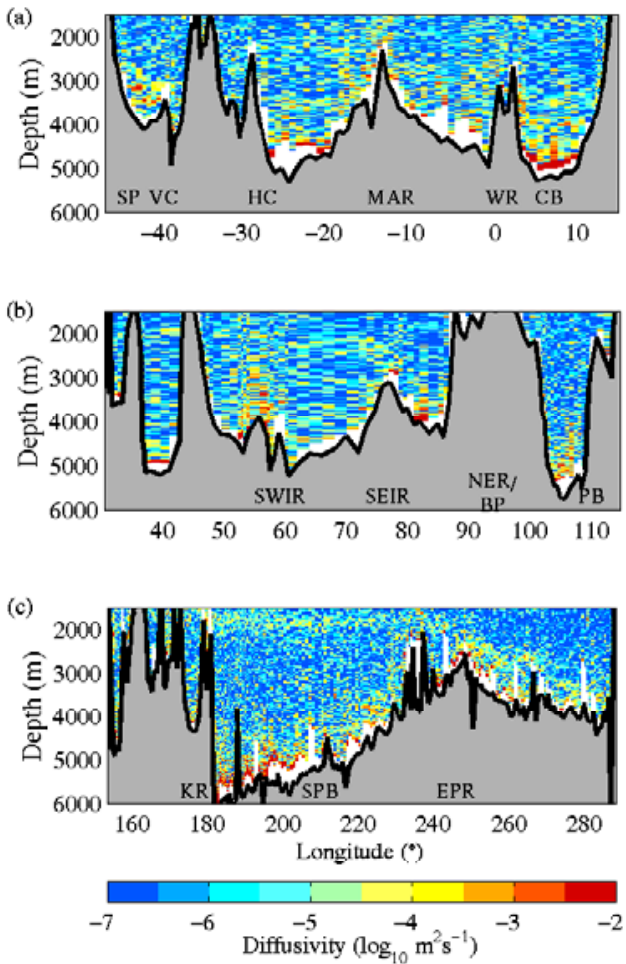

Figure 2. Vertical distribution of diffusivity $\left(\log _{10} \mathrm{~m}^{2} \mathrm{~s}^{-1}\right)$ for zonal sections at approximately $30^{\circ} \mathrm{S}$ in the (a) South Atlantic, (b) Indian and (c) South Pacific. Major topographic features and ocean basins are marked. SP-Santos Plateau, VC-Vema Channel, HC-Hunter Channel, MARMid-Atlantic Ridge, WR-Walvis Ridge and CB-Cape Basin (Figure 2a). SWIR-Southwest Indian Ridge, SEIR - Southeast Indian Ridge, NER/BP-Ninetyeast Ridge and Broken Plateau, and PB-Perth Basin (Figure 2b). KR-Kermadec Ridge, SPB-Southwest Pacific Basin, and EPR-East Pacific Rise (Figure 2c).

the water column is seen on the southern flank of the Ridge.

[12] An enhancement of diffusivity throughout the entire water column is associated with each front in each Southern Ocean sector (Figure 3). In the Atlantic sector of the Southern Ocean, the enhanced diffusivity associated with the Scotia Arc and the APF are clearly separated by a region of lower diffusivity $\left(\mathrm{O}\left(10^{-6} \mathrm{~m}^{2} \mathrm{~s}^{-1}\right)\right)$ between $51^{\circ}$ and $54^{\circ} \mathrm{S}$. Unfortunately, incomplete CTD data near the SAF does not allow for an estimate of diffusivity associated with this front. In the Indian sector of the Southern Ocean the position of the SAF coincides with the southern flank of the Southeast Indian Ridge where there appears to be enhanced diffusivity well above the sea floor. Between the Southeast Indian Ridge and $51^{\circ} \mathrm{S}$ the diffusivity is generally of $\mathrm{O}\left(10^{-5} \mathrm{~m}^{2} \mathrm{~s}^{-\mathrm{P}}\right)$ or less. A marked increase in the diffusivity is found to be associated with the APF. Enhanced diffusivity is generally maintained south of the APF with another distinct water column diffusivity maximum near $55^{\circ} \mathrm{S}$. East of the Kerguelen Plateau there is a confluence between the ACC and the eastward extension of the Kerguelen deep western boundary current (M. S. McCartney and K. A.
Donohue, A deep cyclonic gyre in the Australian-Antarctic basin, submitted to Progress in Oceanography, 2005). This confluence may result in the enhanced diffusivities found south of the APF east of the Kerguelen Plateau. Enhanced water column diffusivity is also associated with the ACC in the Pacific sector.

\section{Discussion}

[13] The spatial and vertical distribution of mixing at $30^{\circ} \mathrm{S}$ in the western Atlantic near the Mid-Atlantic Ridge (Figure 2a) is very similar to the mixing distribution obtained from microstructure measurements in the Brazil Basin [Polzin et al., 1997; Mauritzen et al., 2002]. As in the Brazil Basin mixing experiment, mixing estimates from strain variance show enhanced mixing on the western flank and over the Mid-Atlantic Ridge. Strain variance mixing estimates near the ridge of $\mathrm{O}\left(10^{-3} \mathrm{~m}^{2} \mathrm{~s}^{-1}\right)$ are in agreement with the microstructure mixing values. In this study, enhanced bottom diffusivity is maintained away from the ridge, while in the Brazil Basin mixing experiment diffusivity values $\mathrm{O}\left(10^{-5} \mathrm{~m}^{2} \mathrm{~s}^{-1}\right)$ were found away from the ridge. Note that the hydrographic section used in this study is south of the Brazil Basin mixing observations, and
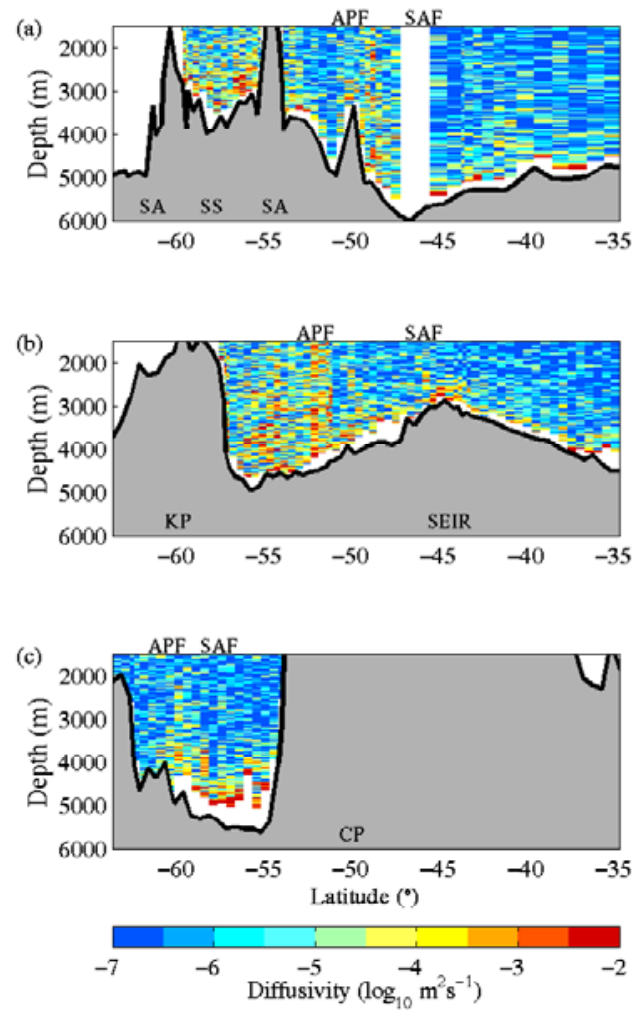

Figure 3. Vertical distribution of diffusivity $\left(\log _{10} \mathrm{~m}^{2} \mathrm{~s}^{-1}\right)$ for meridional sections that cross the ACC in the Southern Ocean sectors: (a) Atlantic; (b) Indian; and (c) Pacific. The position of the SAF and APF are shown on each section. Major topographic features and ocean basins are marked. SA-Scotia Arc, and SS-Scotia Sea (Figure 3a). KPKerguelen Plateau, and SEIR-Southeast Indian Ridge (Figure 3b). CP-Campbell Plateau (Figure 3c). 
enhanced mixing away from the Mid-Atlantic Ridge is estimated north of the Vema and Hunter Channels and over the Santos Plateau, as AABW/LCDW flows into the basin.

[14] Good agreement is found for the estimated order of magnitude of mixing, and the horizontal and vertical distribution of mixing between LADCP/CTD data [Polzin and Firing, 1997; Naveira Garabato et al., 2004] and strain variance techniques. Polzin and Firing [1997] estimate mixing using LADCP/CTD data for the same WOCE section in the Southern Ocean Indian sector (I08). They looked at two groups of 12 stations centered at $35^{\circ} \mathrm{S}$ and $55^{\circ} \mathrm{S}$. The vertical profile of diffusivity at $35^{\circ} \mathrm{S}$ is $\mathrm{O}\left(10^{-5} \mathrm{~m}^{2} \mathrm{~s}^{-1}\right)$ above $3000 \mathrm{~m}$ and diffusivity increases below this level reaching values of $\mathrm{O}\left(10^{-4} \mathrm{~m}^{2} \mathrm{~s}^{-1}\right)$ at the bottom. At $55^{\circ} \mathrm{S}$, average vertical diffusivity is $4.4 \times$ $10^{-4} \mathrm{~m}^{2} \mathrm{~s}^{-1}$. Similar differences in the vertical diffusivity profiles between $35^{\circ} \mathrm{S}$ and $55^{\circ} \mathrm{S}$ are found in the strain variance based mixing estimates (Figure $3 b$ ). In the Scotia Sea, mixing estimates from strain variance (Figure $3 \mathrm{a}$ ) and LADCP/CTD techniques [Naveira Garabato et al., 2004] agree.

[15] Fine and microstructure observations provide direct observation of mixing in specific ocean regions [e.g., Toole et al., 1994; Polzin et al., 1997; Toole et al., 1997], while area-averaged (basin and/or ocean) diffusivity estimates from observational studies based on property conservation provide mixing estimates that do not resolve the spatial variability of mixing within the basins [e.g., Ferron et al., 1998; Sloyan and Rintoul, 2001; Morris et al., 2001]. Order of magnitude diffusivity estimates based on strain variance from CTD profiles are able to bridge the gap between the detailed fine and microstructure observations at specific ocean sites and area averaged estimates of mixing from basin property conservation. Although the detailed information provided by the fine and microscale observations cannot be obtained from the mixing estimates based on CTD data, the global coverage of this data enables assessment of the spatial variability of mixing. Maps of the spatial variability of turbulent mixing could be utilized in both numerical and box models, and indicate sites of future detailed microstructure observations.

[16] The diffusivity distribution in the southern hemisphere oceans is spatially and vertically non-uniform. The enhancement of mixing above rough topography along the zonal sections at $30^{\circ} \mathrm{S}$, agrees with enhanced turbulent diffusivity from local dissipation of the internal tide [St. Laurent et al., 2002]. In addition, enhanced mixing between $\mathrm{AABW}$ and/or LCDW and overlying water masses north of the deep passages through which $\mathrm{AABW} / \mathrm{LCDW}$ flow is noted.

[17] Across the ACC the vertical profile of diffusivity does not decay rapidly with height above bottom. Polzin $[1999,2004]$ present a method for assessing the decay of internal lee waves and tides, respectively, from a source region. In the tidal case, the diffusivity scale height depends upon the barotropic tidal velocity, while for lee waves the diffusivity scale height depends upon the near bottom geostrophic velocity. Differences in the vertical extent of diffusivity profiles between the parameterization of the internal tide and topography, and estimates from strain variance imply that elevated vertical diffusivity profiles in the ACC are due to the bottom velocity differences of the $\mathrm{ACC}$ and tidal oscillation.

\section{Conclusions}

[18] Strain variance from CTD hydrographic sections in the southern hemisphere oceans suggest that deep ocean mixing is vertically and spatially non-uniform. In the Southern Ocean significant mixing throughout the water column is found where the ACC impinges on bottom topography. Detailed fine and microstructure observations in the ACC are needed to fully understand the implication of these high mixing regions on the momentum balance of the $\mathrm{ACC}$, and the role of these Southern Ocean mixing "hotspots" on the size and structure of the global meridional overturning circulation.

[19] Acknowledgments. BMS was supported by the Ocean and Climate Change Institute at the Woods Hole Oceanographic Institution. Numerous discussions with Kurt Polzin, and comments from two anonymous reviewers and Ray Schmitt improved this manuscript. This is WHOI contribution number 11393

\section{References}

Bray, N. A., and N. P. Fofonoff (1981), Available potential energy for MODE eddies, J. Phys. Oceanogr., 11, 30-46.

Cairns, J. L., and G. O. Williams (1976), Internal wave observations from a midwater float, J. Geophys. Res., 81, 1943-1950.

Ferron, B., H. Mercier, K. Speer, A. Gargett, and K. Polzin (1998), Mixing in the Romanche Fracture Zone, J. Phys. Oceanogr., 28, 1929-1945.

Gargett, A. E. (1990), Do we really know how to scale the turbulent kinetic energy dissipation rate $\epsilon$ due to breaking of oceanic internal waves?, J. Geophys. Res., 95, 15,971-15,974.

Garrett, C. J. R., and W. H. Munk (1975), Space-time scales of internal waves: A progress report, J. Geophys. Res., 80, 291-297.

Gregg, M. C. (1989), Scaling turbulent dissipation in the thermocline, J. Geophys. Res., 94, 9686-9698.

Jayne, S., and L. St. Laurent (2001), Parameterizing tidal dissipation over rough topography, Geopyhs. Res. Lett., 28, 811-814.

Jayne, S., L. St. Laurent, and S. Gille (2004), Connections between ocean bottom topography and Earth's climate, Oceanogr., 1, 65-74.

Kunze, E. (2003), Yes, we have no abyssal mixing, in Near-Boundary Processes and Their Parameterization, edited by D. Müller and D. Henderson, pp. 85-93, Univ. of Hawai'i at Monoa, Honolulu.

Mauritzen, C., K. L. Polzin, M. S. McCartney, R. C. Millard, and D. E. West-Mack (2002), Evidence in hydrography and density finestructure for enhanced vertical mixing over the Mid-Atlantic Ridge in the western Atlantic, J. Geophys. Res., 107(C10), 3147, doi:10.1029/2001JC001114.

Morris, M. Y., M. M. Hall, L. C. St. Laurent, and N. G. Hogg (2001), Abyssal mixing in the Brazil basin, J. Phys. Oceanogr., 31, 33313348.

Naveira Garabato, A. C., K. L. Polzin, B. A. King, K. J. Heywood, and M. Visbeck (2004), Widespread intense turbulent mixing in the Southern Ocean, Science, 303, 210-213.

Orsi, A. H., T. Whitworth III, and W. D. Nowlin Jr. (1995), On the meridional extent and fronts of the Antarctic Circumpolar Current, Deep Sea Res., Part I, 42, 641-673.

Osborn, T. R. (1980), Estimates of the local rate of vertical diffusion from dissipation measurements, J. Phys. Oceanogr., 10, 83-89.

Polzin, K. (1999), A rough recipe for the energy balance of quasi-steady internal Lee waves, in Internal Wave Modelling, edited by D. Müller and D. Henderson, pp. 117-128, Univ. of Hawai'i at Monoa, Honolulu.

Polzin, K. (2004), Idealized solutions for the energy balance of finescale internal wave field, J. Phys. Oceanogr., 34, 231-246.

Polzin, K. L., and E. Firing (1997), Estimates of diapycnal mixing using LADCP and CTD data from I8S, Int. WOCE Newsl., 29, 39-42.

Polzin, K. L., K. G. Speer, J. M. Toole, and R. W. Schmitt (1996), Intense mixing of Antarctic Bottom Water in the equatorial Atlantic Ocean, Nature, 380, 54-57.

Polzin, K. L., J. M. Toole, J. R. Ledwell, and R. W. Schmitt (1997), Spatial variability of turbulent mixing in the abyssal ocean, Science, 276, 93-96

Sloyan, B. M., and S. R. Rintoul (2001), The Southern Ocean limb of the global deep overturning circulation, J. Phys. Oceanogr., 31, $143-$ 173 . 
St. Laurent, L. C., J. M. Toole, and R. W. Schmitt (2001), Buoyancy forcing by turbulence above rough topography in the abyssal Brazil Basin, J. Phys. Oceanogr., 31, 3476-3495.

St. Laurent, L. C., H. L. Simmons, and S. R. Jayne (2002), Estimating tidally driven mixing in the deep ocean, Geophys. Res. Lett., 29(23), 2106, doi:10.1029/2002GL015633.

Stommel, H., and A. B. Arons (1960), On the abyssal circulation of the world ocean-II. An idealized model of circulation pattern and amplitude in oceanic basins, Deep Sea Res., 6, 140-154.

Toole, J. M., K. L. Polzin, and R. W. Schmitt (1994), Estimates of diapycnal mixing in the abyssal ocean, Science, 264, 1120-1123.
Toole, J. M., R. Schmitt, K. Polzin, and E. Kunze (1997), Near-boundary mixing above the flanks of a midlatitude seamount, J. Geophys. Res., $102,947-959$.

Wijesekera, H., L. Padman, T. Dillon, M. Levine, and C. Paulson (1993), The application of internal-wave dissipation models to a region on strong mixing, J. Phys. Oceanogr., 23, 269-286.

B. M. Sloyan, CSIRO Marine and Atmospheric Research, GPO Box 1538 Hobart, TAS 7001, Australia. (Bernadette.Sloyan@csiro.au) 